\title{
DESIGN AND FABRICATION OF AN ACCUMULATOR CONTAINER/ BATTERY PACK FOR A FORMULA STUDENT VEHICLE
}

\author{
Ujjwal Ashish ${ }^{1}$, Bishav Raj ${ }^{2}$, Abhishek Kumar ${ }^{3}$ \\ ${ }^{1}$ B.Tech (EEE), Vellore Institute of Technology, Tamil Nadu, India \\ ${ }^{2}$ B.Tech (Mechanical), Vellore Institute of Technology, Tamil Nadu, India \\ ${ }^{3}$ B.Tech (EEE), Vellore Institute of Technology, Tamil Nadu, India
}

\begin{abstract}
This paper reflects the mind set and philosophy for designing the Accumulator Container for VIT University's Formula Student Electric Vehicle. The vehicle is made according to the rules specified by the Formula SAE (FSAE). The competition is aimed at designing a single seat race car under certain rules and regulations. The static, dynamic and functional requirements are established and the electrical and mechanical aspects of the battery pack are simulated. It also takes into account the Battery Management System, Powertrain and energy requirements along with a brief description of the overall electrical system of the vehicle.
\end{abstract}

Keywords: Battery Pack, Cell Chemistry, Cell Configuration

\section{INTRODUCTION}

Electric and hybrid vehicles depend on electrochemical battery systems, with lithium-ion and different types of lithium polymer chemistries which are most widely used in terms of power density, performance and efficiency. However, the electrical, mechanical and thermal integration of cells into packs and packs into electrical vehicles is paramount in order to ensure long and safe operation. The problematic part comes into play during the integration process. The electrical monitoring and testing of individual cells can be done along with the thermal and cooling analysis of the entire module within the accumulator container. The discharge rate, cell voltages and cell temperatures are constantly monitored by the Battery Management System. Mechanical integrity is crucial, and the challenge here, given the relatively high energy densities of batteries is to minimize weight and the use of additional support materials, whilst providing adequate support and protection particularly in crash scenarios. The FSAE Rules clearly dictate the guidelines related to the mechanical configurations and stability which can be achieved by ANSYS Simulation and Analysis.

\subsection{Introduction to Tractive System}

In order to maximize the battery life and efficiency, the module design and battery management approach should be improvised. The current drawn, discharge/charge rate and operating and storing temperature is important in determining the lifetime of Lithium based Cells. Batteries are particularly intolerant to temperature extremes, with high temperatures being encountered during high current loading conditions such as fast charging or acceleration transients which cause large specific internal heat generation which in turn causes changes in the internal resistances. This is primarily due to resistive heating in the contacts.

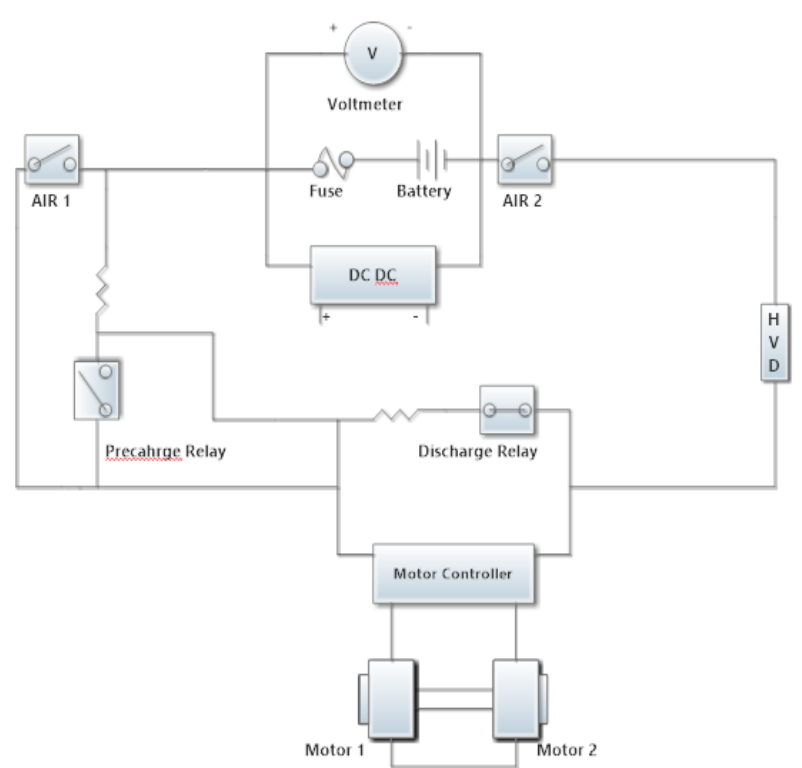

Chart -1: Tractive System Schematic

The schematic shows the tractive system of the vehicle which includes the AIRs (Accumulator Isolation Relays) used to isolate the battery pack from the entire system. Kilovac 200 series AIRs are used for the same. The precharge relay is used to prevent inrush current as soon as the HVD (High Voltage Disconnect) completes the circuit. The DC-DC converter is used to power up the Low Voltage and ECU system. The car uses two Agni 95R motor in series through a mechanical coupling. The motor has high efficiency (about 93\% maximum) giving longer running time and less frequent battery replacement. 
Table -1: Motor Specifications

\begin{tabular}{|c|c|}
\hline $\begin{array}{c}\text { Motor Manufacturer } \\
\text { and Type }\end{array}$ & $\begin{array}{c}\text { Agni 95R PMDC } \\
\text { Motor }\end{array}$ \\
\hline Motor principle & Permanently excited \\
\hline $\begin{array}{c}\text { Maximum } \\
\text { continuous power }\end{array}$ & $16 \mathrm{~kW}$ \\
\hline Peak power & $30 \mathrm{~kW}$ for 5s \\
\hline Input voltage & $72 \mathrm{VAC}$ \\
\hline Nominal current & $220 \mathrm{~A}$ \\
\hline Peak current & $460 \mathrm{~A}$ \\
\hline Maximum torque & $52 \mathrm{~N}-\mathrm{m}$ \\
\hline Nominal torque & $26 \mathrm{~N}-\mathrm{m}$ \\
\hline Cooling method & Air \\
\hline
\end{tabular}

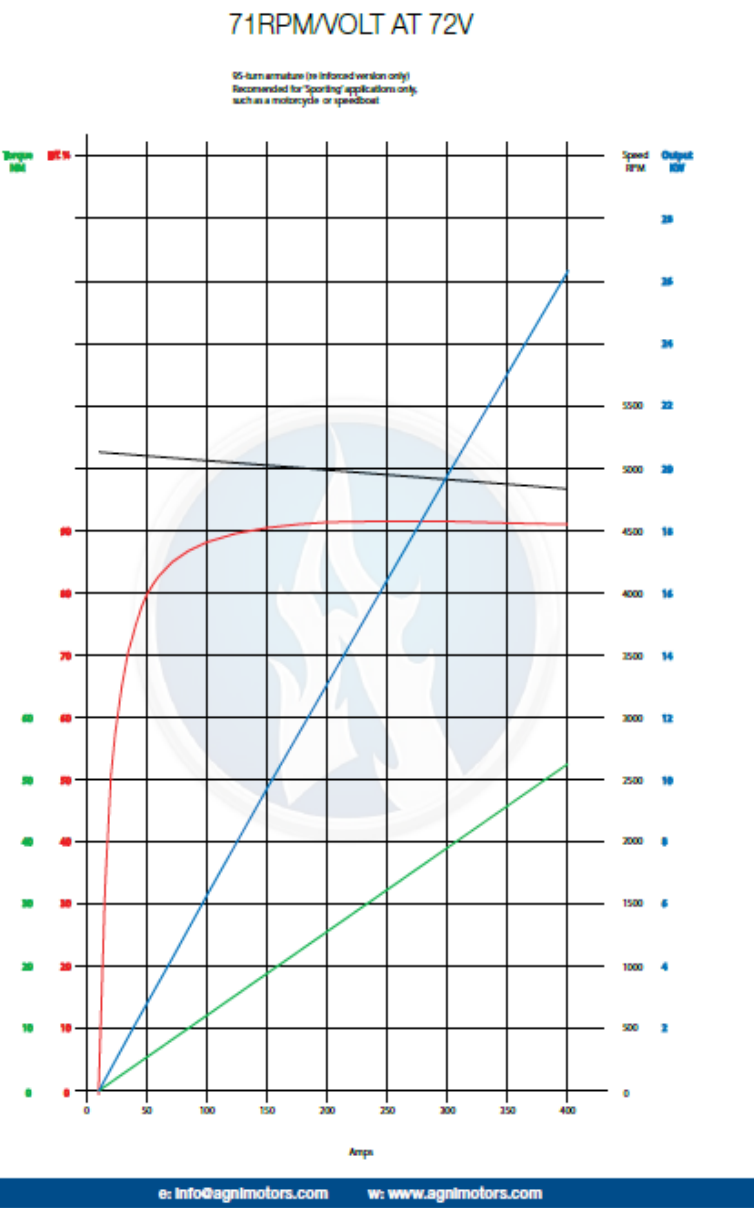

Chart -2: AGNI 95R Graph for 72Volts [6]

\subsection{Motor Controller}

A motor controller controls the overall performance of the motor. As shown in Figure 1, a single motor controller is used to drive 2 AGNI 95R motors coupled in series. It controls the voltage being supplied to the motor from the accumulator container. The voltage supplied to the motor is proportional to the output signal of accelerator pedal. Kelly's programmable PMDC motor controller provide highly efficient, smooth and quiet controls for electric vehicles. It uses a combination of powerful microprocessor, MOSFET, PWM to achieve $97 \%$ efficiency. It is regenerative braking enabled along with $\mathrm{CAN}$ bus module.

Table -1: Motor Controller Specifications

\begin{tabular}{|c|c|}
\hline Motor controller type & $\begin{array}{l}\text { Kelly Controller } \\
\text { HPM14501 }\end{array}$ \\
\hline $\begin{array}{l}\text { Maximum continuous } \\
\text { power }\end{array}$ & $32.4 \mathrm{KW}$ \\
\hline Maximum peak power & $72 \mathrm{~kW}$ for 1 minute \\
\hline $\begin{array}{l}\text { Maximum Input } \\
\text { voltage: }\end{array}$ & 168VDC \\
\hline Output voltage: & 144VDC \\
\hline $\begin{array}{l}\text { Maximum continuous } \\
\text { output current: }\end{array}$ & $225 \mathrm{~A}$ \\
\hline $\begin{array}{l}\text { Maximum peak } \\
\text { current: }\end{array}$ & 500A for 1 minute \\
\hline Control method & Analog Signal \\
\hline Cooling method: & Air \\
\hline $\begin{array}{c}\text { Auxiliary Supply } \\
\text { Voltage }\end{array}$ & 8-30VDC \\
\hline
\end{tabular}

The controller reads the current reference signal and compares it with the current that it's on the armature circuit. Depending on this difference, the controller supplies a voltage that makes the armature current follow the reference value. The controller gets its value from a potentiometer box, used as a throttle sensor. The potentiometer range is 0 $5 \mathrm{Kohm}$.

\section{Cell Chemistry}

For the purpose of Electric Vehicles, there are a lot of options available as primary energy sources. The most essential part in building an Electric Vehicle is the selection of the Cell type or Cell Chemistry. [1] Moreover, the optimization of the selected cell type and battery pack configuration which in turn is determined by the powertrain requirements, leads to better results which is only possible through rigorous testing along with simulation and analysis. The criterion for selection of Cell Chemistry for an Electric Vehicle is-

- High Energy Density (Wh/Kg)

- High Specific Energy Density (Wh/l)

- High Power Density (KW/Kg)

- Fast Charging and Discharging Ability

- Longer Life Cycles

- Eco-Friendly 
There are a lot of options available as sources for Electric Vehicles (EV), be it VRLA(Valve Regulated Lead Acid Battery), NiCd(Nickel Cadmium), NiMH(Nickel Metal Hydride),C-Zn(Carbon Zinc), Li-Ion(Lithium Ion) and LiPo(Lithium Polymer, which has more sub varieties like
Pouch and Prismatic Types).The parameters for each battery type is given in Fig2. The parameters may differ from one manufacturer to the other, but these values are taken as general values.

\begin{tabular}{|l|l|l|l|l|l|l|}
\hline PROPERTIES & VRLA & C-Zn & NiMH & NiCd & Li-ion & Li-Po \\
\hline Specific Energy (Wh/Kg) & $33-42$ & 36 & $60-80$ & $40-60$ & $90-133$ & $150-260$ \\
\hline Specific Energy Density(Wh/l) & $60-110$ & 92 & $140-300$ & $50-150$ & $250-676$ & $250-730$ \\
\hline Specific Power (W/Kg) & 180 & $10-27$ & $250-1000$ & 150 & $250-340$ & $300-350$ \\
\hline Life Cycles & $500-800$ & N/A & $500-2000$ & 2000 & $400-1200$ & $600-800$ \\
\hline Cost Of Development(US\$/kWh) & 150 & $90-110$ & $250-300$ & 300 & 250 & N/A \\
\hline Charge-Discharge Efficiency (\%) & $50-95$ & $50-60$ & 66 & $70-90$ & $80-90$ & $80-95$ \\
\hline
\end{tabular}

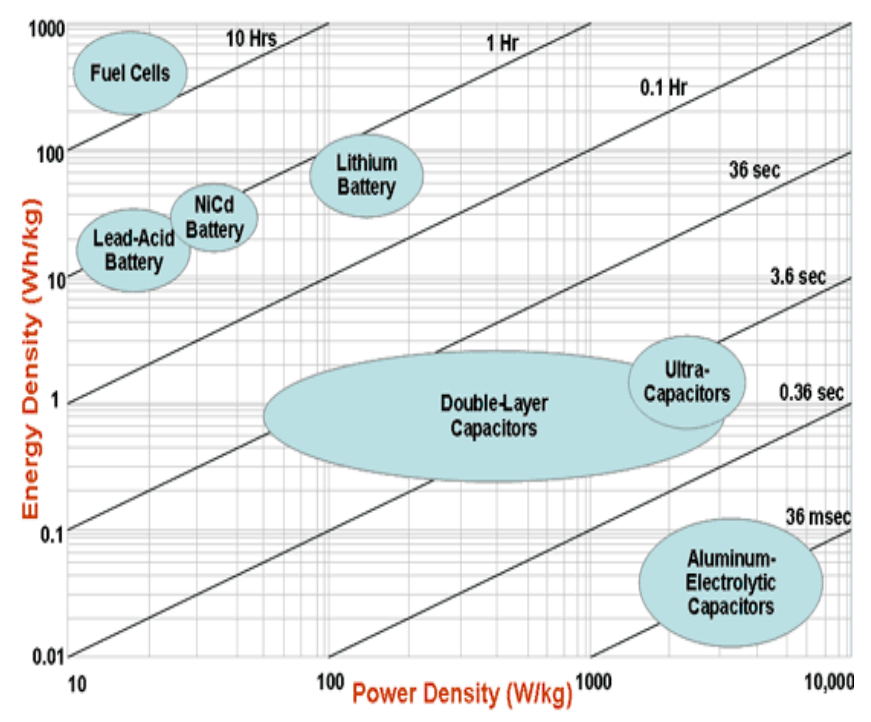

Chart -3: Ragone Plot for Energy Storage

NiMH (Nickel Metal Hydride) have a moderate to higher specific energy value but have reduced life cycles as compared to NiCd (Nickel Cadmium). NiCd batteries have relatively low specific energy density but are well matured with decent specific power value. These have a good life cycle value but are not environment friendly and hence are not well suited for electric vehicle applications. Due to an exponential advancement in the field of battery technology the use VRLA (Valve Regulated Lead Acid) has been extremely limited in the field of Electric Vehicles. The idea behind developing an Electric Vehicle is for it to be safe, batteries do not fit into this criteria, hence are not suitable for $\mathrm{EV}$ applications.

Li-Ion is one of the fastest growing technologies in the field of cell chemistries. [2] This is because it has extremely high Specific Energy Density along with an impeccable Power density value. The life cycle value can be considered to be moderate, since it is capable of producing $80-90 \%$ charge- discharge efficiency. The only drawback with Li-ion cell chemistry is that it is fragile in nature and has to be monitored by a protection circuit. Storage of the cells is also an important point to consider. These cells are extremely sensitive to temperature and over-heating. A Phenomenon called "Thermal Runaway" is very commonly seen in Li-Ion batteries. This condition is defined as situation where an increase in temperature causes a change in the properties and dynamics which in turn leads to further increase in temperature, leading to an undesirable result .It is recommended to store these type of cells in an ambient temperature of $15^{\circ} \mathrm{C}\left(59^{\circ} \mathrm{F}\right)$.

Li-Polymer or Li-Po as it is generally known as, incorporates all the properties and parameters of Li-ion cells, with the additional advantage of it being slimmer in geometry and light weight.[3] The significance of the word "polymer" is that a layer of polymer is used instead of a porous separator which is used for the exchange of ions. There are two kinds of specifications for Li-Po batteries - 1 . Dry Type and 2. Gelled Type.

The dry type is extremely stable and can be used for hostile applications. One major drawback with this type is poor conductivity as compared to gelled type. The gelled polymer electrolyte is used to enhance the capacity, conductivity and performance of the cell. It has high specific energy density $(150-260 \mathrm{Wh} / \mathrm{Kg})$ and power density values, and its discharge and charge rate can be easily monitored and controlled by an efficient battery management system. The research, analysis and testing of Li-Polymer cells have shown excellent results and great promise. The shape and size of the cells can be rendered and altered according the energy requirements and design specifications. Hence Li-ion and Li-Po are well suited for EV applications due to its durability and high performance values under different load conditions. 


\section{Transmission Calculations}

The energy and power requirements for the transmission is determined by simulating the vehicle in optimum Lap, where in the parameters of the circuit track are modelled and the minimum energy required to complete one lap is found out. Similarly the energy required to complete 22 laps in the endurance event. The calculations for the power and energy requirements are given below-

Approximate weight of the vehicle (with driver) : $300 \mathrm{~kg}$

Minimum run time required $\quad: 25 \mathrm{~min}$

Minimum energy required to complete endurance (Transmission Requirement) : 6960Whr

Average time required to finish one lap (Average distance per lap/Average Speed $): 1.2 \mathrm{~km} /(52.5 \mathrm{~km} / \mathrm{hr})=82.82 \mathrm{sec}$

Therefore, average power required (average energy/ time) : $6960 \mathrm{Whr} /((82.28 * 18) / 3600)=6960 \mathrm{Whr} / 0.4114 \mathrm{hr}=$ $16917.8 \mathrm{~W}=16.917 \mathrm{KW}$

For combination of 2 Agni 95R motors in series, power required from 1 motor $\quad: \quad 16.917 \mathrm{KW} / 2=8.458 \mathrm{~kW}$

Corresponding to $8.458 \mathrm{~kW}$ at $72 \mathrm{~V}$ current from the motor characteristics is nearly $\mathbf{1 1 7 . 4 7} \mathbf{A}$, therefore, average continuous current is well within the limits of cell capacity. Battery configurations (using SLPB110255255H Pouch Cells) are as follows-

Model calculation (using SLPB110255255H cell)-

$\begin{array}{ll}\text { Power } & =16.917 \mathrm{~kW} \\ \text { Capacity } & =63 \mathrm{Ah} \\ \text { Continuous discharge rate, H } & =7.5 \mathrm{C} \\ \text { Voltage }(40 \mathrm{~S} 1 \mathrm{P}) & =168 \\ \text { Current }(\mathrm{P} / \mathrm{V}) & =100.69\end{array}$

Using Peukert's formula

$\left(\mathrm{It}=\mathrm{C}(\mathrm{C} /(\mathrm{IH}))^{\wedge}(\mathrm{k}-1)\right)$

$$
=63((63 /(100.69 * 7.5)))^{\wedge}(1.1-1)
$$

Effective run time $\left(\mathrm{t}=\mathrm{H}(\mathrm{C} /(\mathrm{IH}))^{\wedge} \mathrm{k}\right)$

$=(7.5) \times(49.14 /(10.69 * 7.50))^{\wedge} 1.1 \mathrm{hr}$

Hence Transmission Requirements are $16.917 \mathrm{KW}$, according to the lap timings simulated in optimum software. For Battery Design, the effective run time is decreased to $22.25 \mathrm{~min}$ and the Discharge rate is $49.14 \mathrm{Ah}$, hence the new battery energy is $49.14 \mathrm{Ah} * 40 * 4.2=8225.52 \mathrm{Whr}$, which is more than the required energy. Power of the Battery Pack is also changed with respect to the new values, power=Energy/Time

8225.52Whr/22.25Min= $22.312 \mathrm{KW}$, which is also well within range and compensates for all the losses in transmission and battery pack connections.

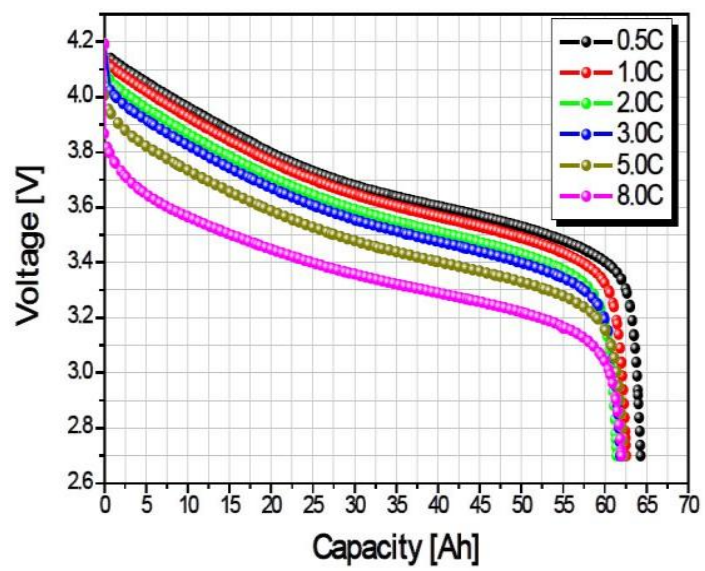

Chart -4: Capacity V/S Voltage Graph[5]

\section{Cell Packing and Configuration}

The Accumulator container consisted of 40 63Ah (at a $7.5 \mathrm{C}$ discharge rate) Kokam Lithium-polymer pouch cells with a maximum and minimum operating voltage limit of $4.2 \mathrm{~V}$ and $2.7 \mathrm{~V}$ respectively. The cells have a rated capacity of 233.1Whr (Nominal Capacity) with the maximum discharge current of each cell is $480 \mathrm{~A}$ and maximum peak current of 720 A.

There are basically 2 ways of connecting cells in order to make a battery pack (accumulator pack)-

- Series

- Parallel

Connecting the cells in series increases the total voltage of the battery pack, and the cells experience the same current. Adding cells in parallel keeps the voltage value as constant, and the current from each cell in parallel gets added. The advantage with parallel configuration is the fact that it can be used to balance the cell voltages. . However, extremely precarious protection circuits should be used in case of parallel configuration. In the event of one cell being damaged, all the cells in parallel will try to passively balance the faulty cell which may lead to disastrous results. There are various BMS (Battery Management Systems) used to balance the cell voltages and monitor the discharge rate of the cells.

The Battery Management System (BMS) used to monitor the cell voltages as well as cell temperatures is manufactured by E-Lithion. The cell boards are attached to each cell connected in series. Cell boards are the temperature sensing and voltage measuring devices. The battery pack has a configuration of $40 \mathrm{~S} 1 \mathrm{P}$, hence 40 cell boards are used to monitor the overall functioning of the battery pack. The data from each cell is hard wired into the BMS Master Controller. The Master Controller depending on the values of the cell voltages and temperature, sends a signal to the Shutdown Safety Circuit. The Shutdown Safety Circuit is responsible for shutting down the High Voltage or Tractive System in case of a fault. The Power to the motors is cut off during after the detection of a fault. A fault can be defined in 3 aspects- 
- Cell Voltage goes below 2.7V

- Cell Voltage goes above $4.2 \mathrm{~V}$

- Temperature of a cell goes above 45 degrees Celsius

The fault temperature value can be set by changing the settings of the BMS Master Controller. In EV applications, the ideal maximum temperature for Li-Po cells is 45degrees. If the cell temperature goes above that value, it creates a potentially hazardous scenario. It can lead to thermal runway, which can further lead to an explosion or fire. Hence it is advisable to keep the limit at 45Degrees.

The battery pack contains 40 cells in series with a combined power of $22.312 \mathrm{KW}$. The entire battery pack is divided into stacks of 5 cells each, hence 8 stacks. According to FSAE EV rules, EV 3.3.3 states that "Maintenance plugs, additional contactors or similar measures have to be taken to allow electrical separation of the internal cell segments such that the separated cell segments contain a maximum static voltage of less than 120VDC and a maximum energy of $6 M J$. The separation must affect both poles of the segment" Each stack contains 5 cells of $63 \mathrm{Ah}$ with maximum voltage of $4.2 \mathrm{~V}$. The KWh of one stack is $5 * 63 * 4.2=1323 \mathrm{Whr}$. The energy of each stack will be $1323 \mathrm{Whr} * 3600=4.7 \mathrm{MJ}$, which is clearly rules compliant. This energy separation is achieved by using maintenance plugs or Anderson Connectors. Each pole of the stack is connected to one maintenance plug, which can easily be disconnected without the use of any tools. This methodology helps us to isolate each stack from one another and hence from the entire Battery Pack.

\section{Mechanical Design}

Cells being of pouch form, it is a huge risk to weld the two terminals in order to connect them in series. Four M4 holes were drilled to screw the two terminals together. For more rigidity, aluminum tabs are made. The positive and negative of two cells are sandwiched together between these Nickel plated aluminum tabs. Ni-plating on the tabs are done to avoid any form of corrosion due to high temperature. Though there is space this is the best possible and cheaper method of connection with the available resources.

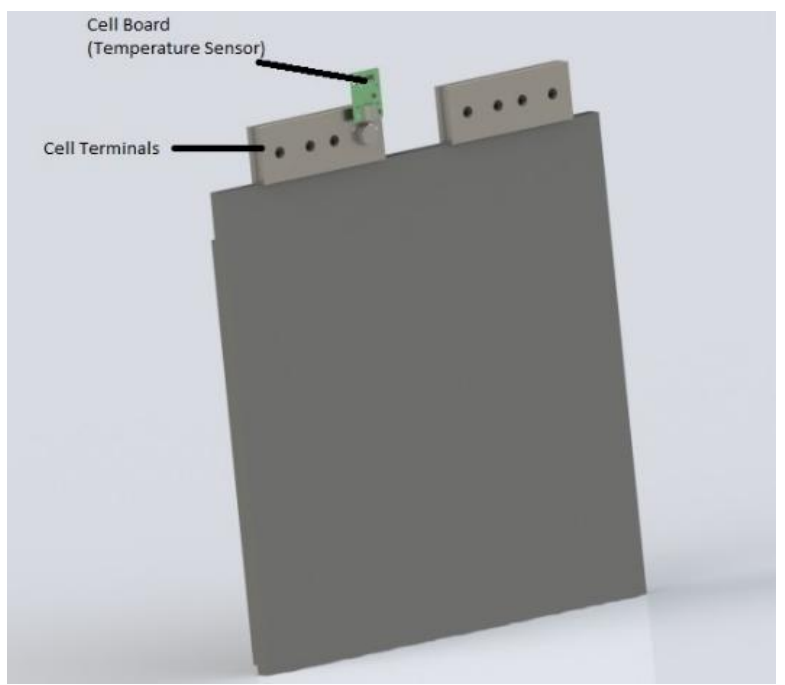

Fig -1: Cell with Cell Board
The temperature sensor (e-lithion) is to be mounted on the negative terminal of the cell. The sensor is also bolted on Ni-plated aluminum tab. For each stack there are 4 or 5 sensors which would give input to the BMS.

\subsection{Pack Architecture}

The design of the pack is a simple cuboidal shape for ease of manufacturing. The material chosen for the pack is Al-6061 T6 taking the weight and strength of welding into consideration. Instead of molding the container, plates are made which are welded onto each other. The main reason for going for welding is due to variation in thickness of the bas plate and perimeter and internal vertical walls. The thickness of the bas plate is $4 \mathrm{~mm}$ while the thickness of the wall is $3 \mathrm{~mm}$ which was the minimum criteria as directed by FSAE rule: EV3.4.6.

The pack is divided into eight compartments for each rack. The separation is achieved through aluminum plates which are welded onto the base plate. The height of the internal vertical walls are $75 \%$ of the height of the perimeter wall. The total weight of the accumulator exceeded $40 \mathrm{~kg}$ which is $80 \mathrm{~kg}$ to be exact, thus it is fastened to the chassis by ten M10 fasteners

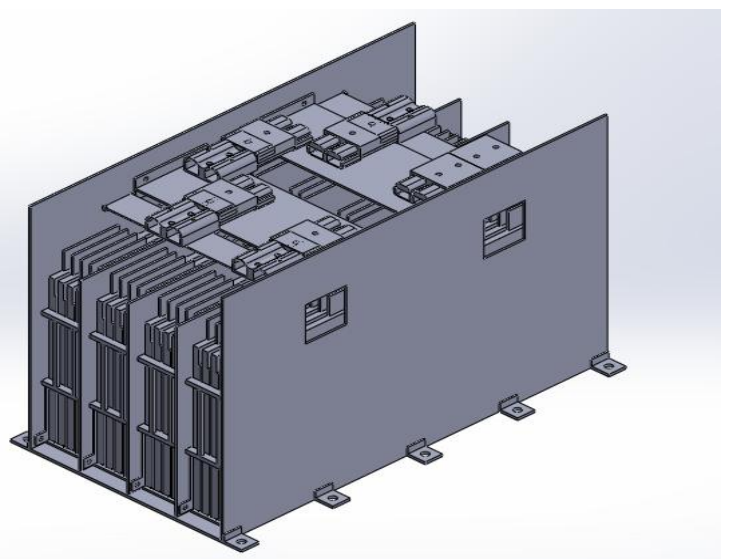

Fig -2: Isometric View of Battery Pack

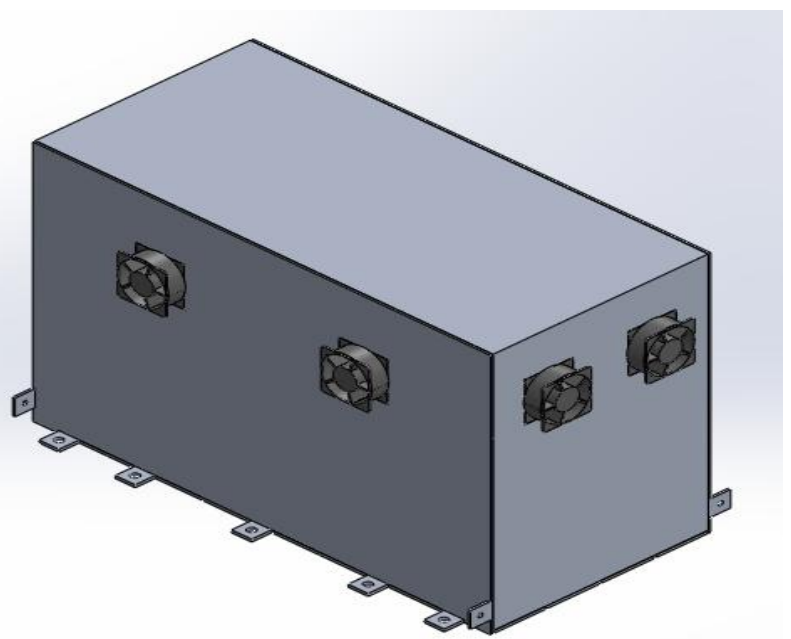

Fig -3: Battery Pack with Lid 


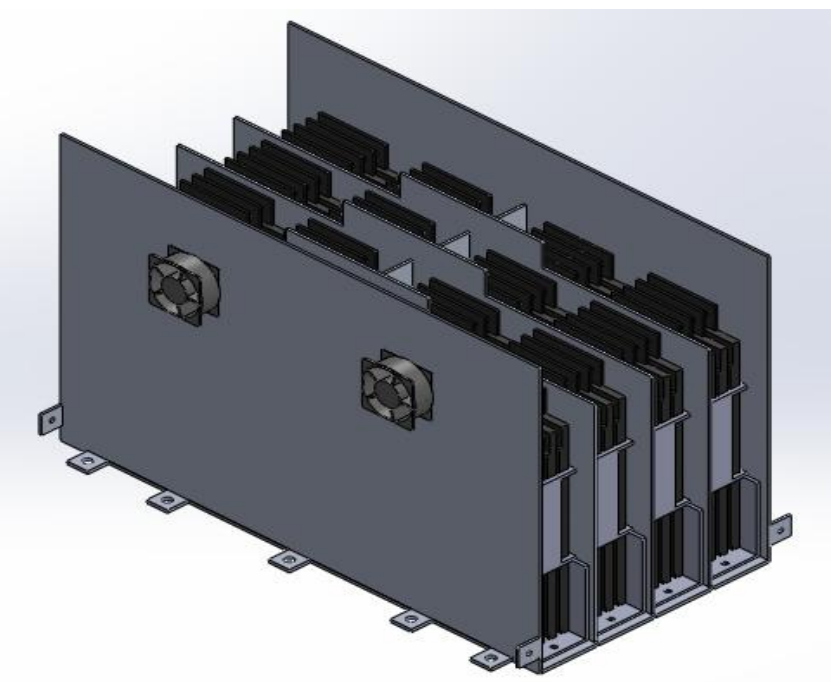

Fig -4: Battery Pack with slots shown

Six fans are added at the height of the terminals for better cooling. Cell terminals are considered to be the hottest part of the cell which requires efficient cooling. Out of the six fans, four fans of 20CFM at the sides act as inlet while the two of 40CFM at the rear as outlet. The capacity of the outlet fan is twice that of inlet to avoid any trapping of air in between the cells.

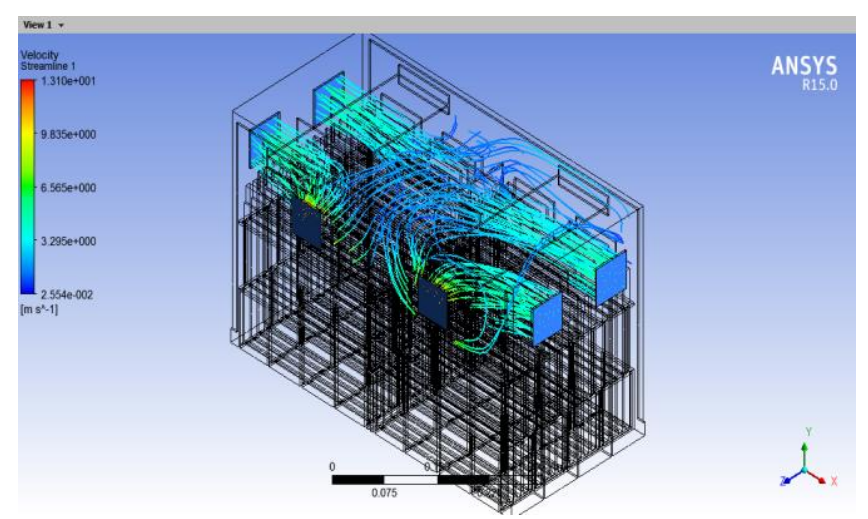

Fig -5: Air flow within the Battery Pack

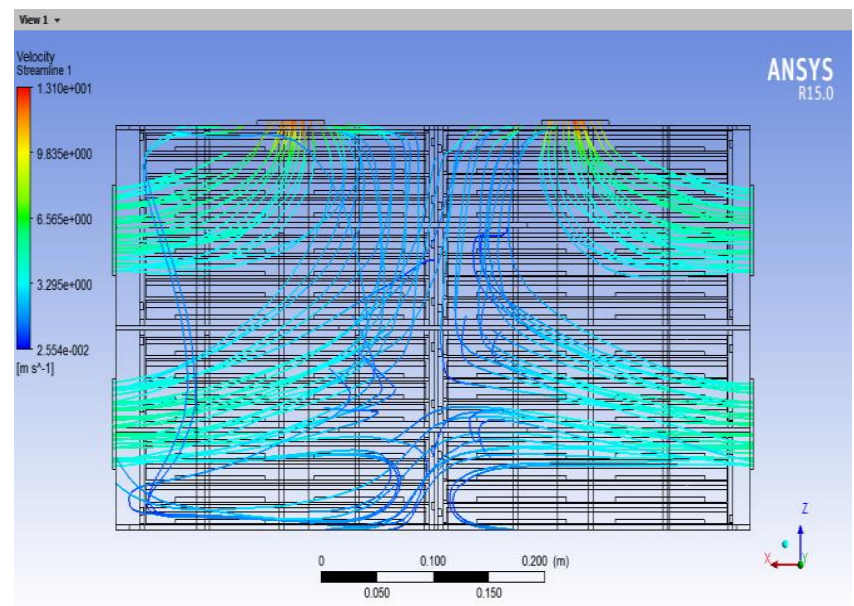

Fig -6: Top View of the Air Flow in the Battery Pack

\subsection{Rack Construction}

A constant separation between each cell is $2 \mathrm{~mm}$ which is maintained by racks. It comprises of two rectangular plates at a distance of $100 \mathrm{~mm}$, the rectangular plates have 5 slits for the cells to pass through. The two rectangular plates are joined by a rectangular plate welded at two opposite sides of its end. The material for rack is aluminum (Al-6061 T6) which underwent $\mathrm{CNC}$ machining to obtain the slits. The thickness of the two plates is $5 \mathrm{~mm}$. The racks are made so that the cells will not move due to inertia and there is no chance for any two terminal short circuiting each other. As a precautionary measure silicon sheet is placed between the terminals of the two cells to avoid short circuiting of the cell terminals.

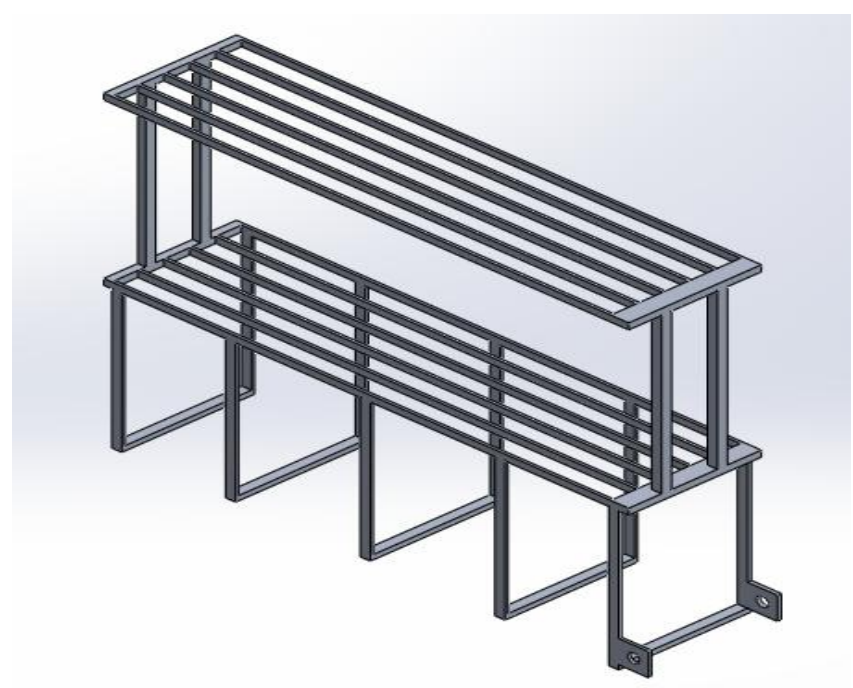

Fig -7: Rack design

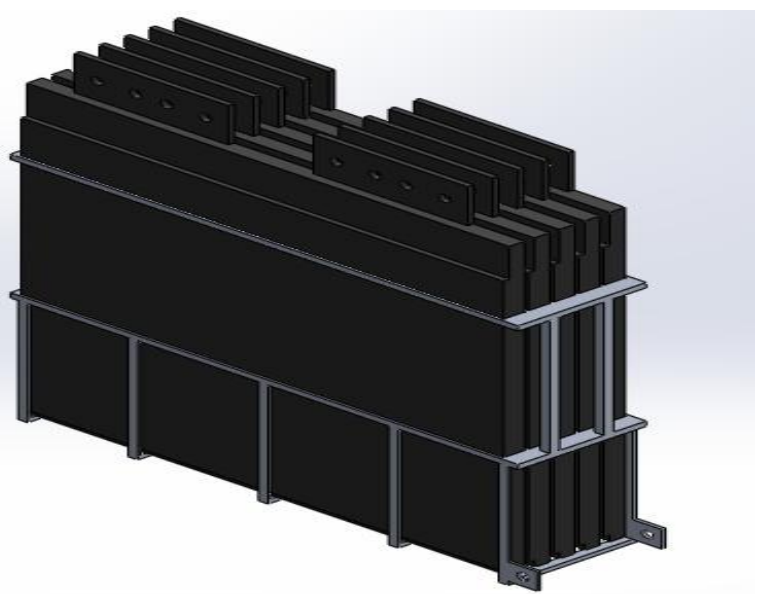

Fig -8: Rack with Cells Stacked

According to FSAE Rules the cell/segment mounting system must be designed to withstand the following acceleration:

a. $40 \mathrm{~g}$ in the longitudinal direction (forward/aft)

b. $40 \mathrm{~g}$ in the lateral (left/right)

c. $20 \mathrm{~g}$ vertical (up/down) direction[4] 


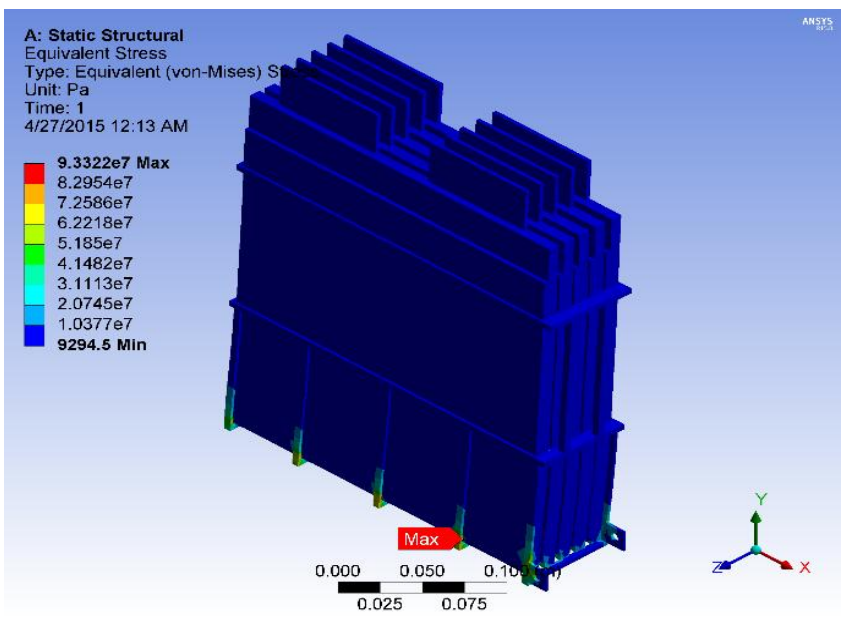

Max Stress: 9.33e7 Pa

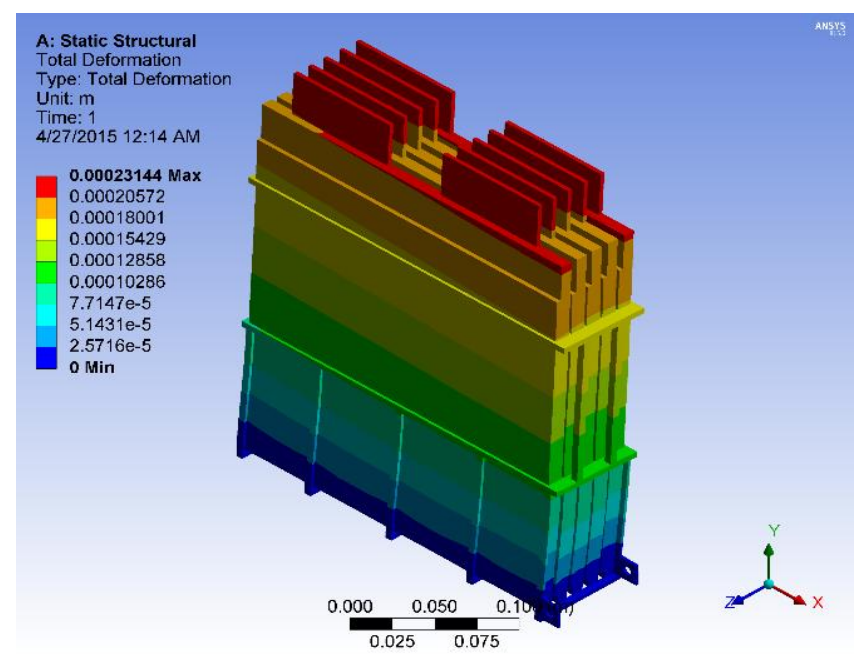

Max Deformation: 2.31e-4 m

The accumulator design guidelines are intended to create a structure that does not fail the following accelerations:

a. $40 \mathrm{~g}$ in the longitudinal direction (forward right)

b. $40 \mathrm{~g}$ in the lateral (left/right)

c. $20 \mathrm{~g}$ vertical (up/down) direction[4]

The analysis is done by providing fixed support the ten bolt holes. The particular analysis is done to make sure that the accumulator container remains intact and the cells are not damaged under impact or collision. Stress analysis and total deformation of the pack for $40 \mathrm{~g}$ acceleration in lateral direction-

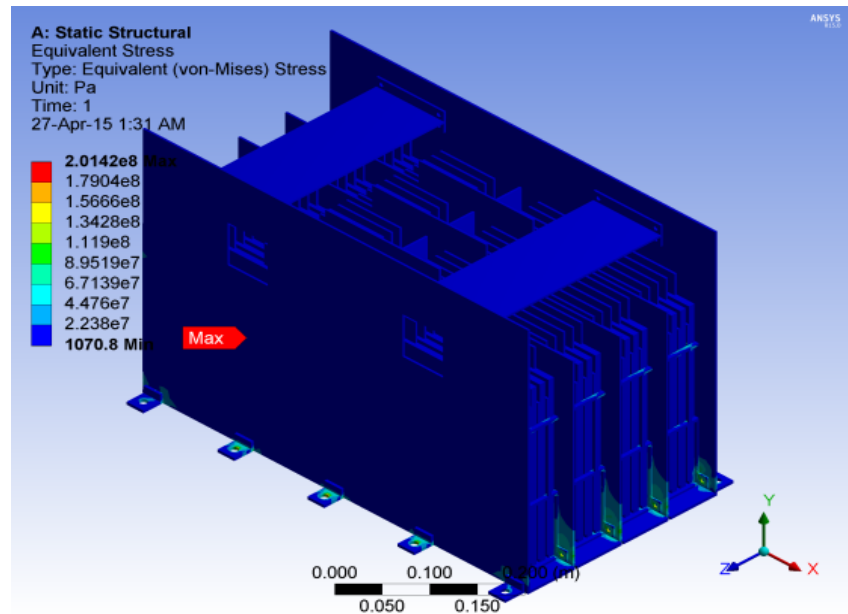

Stress analysis of the pack for $40 \mathrm{~g}$ acceleration in lateral direction

Max Stress: 2.01e8 PA

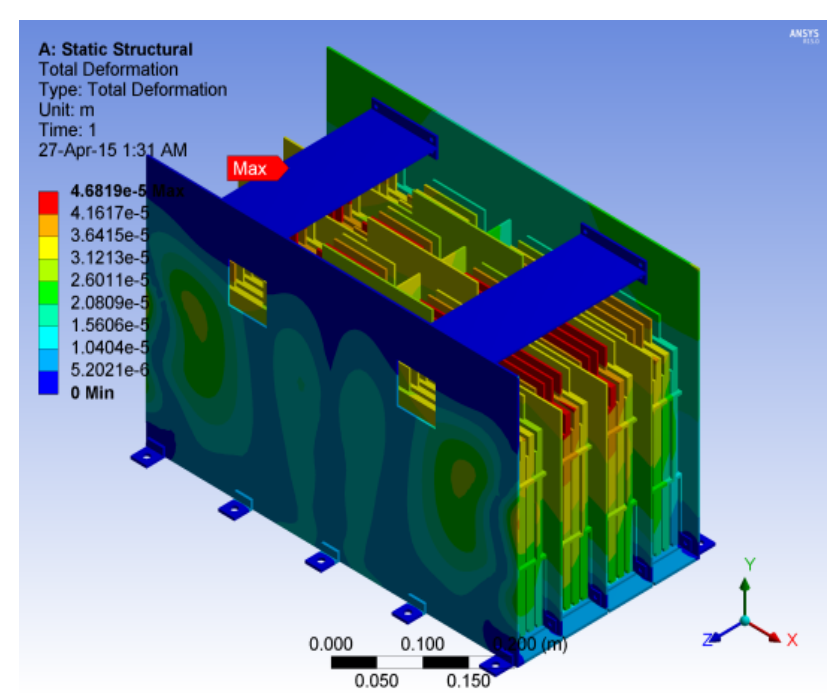

Total deformation of the pack for $40 \mathrm{~g}$ acceleration in lateral direction.

Max Deformation: 4.68e-5m

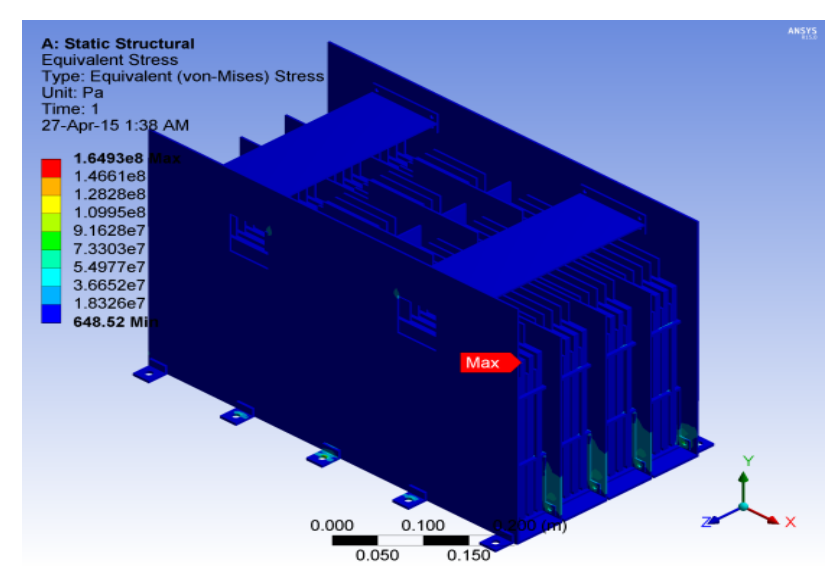

Stress analysis of the pack for $20 \mathrm{~g}$ acceleration in vertical direction

Max Stress: $1.64 \mathrm{e} 8 \mathrm{~Pa}$ 


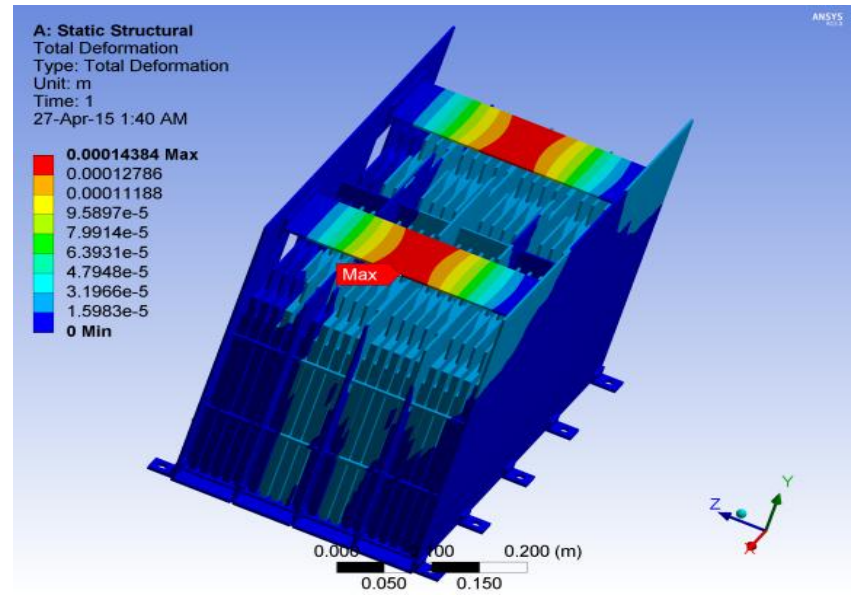

Total deformation of the pack for $20 \mathrm{~g}$ acceleration in vertical direction

Max Deformation: $1.43 \mathrm{e}-4 \mathrm{~m}$

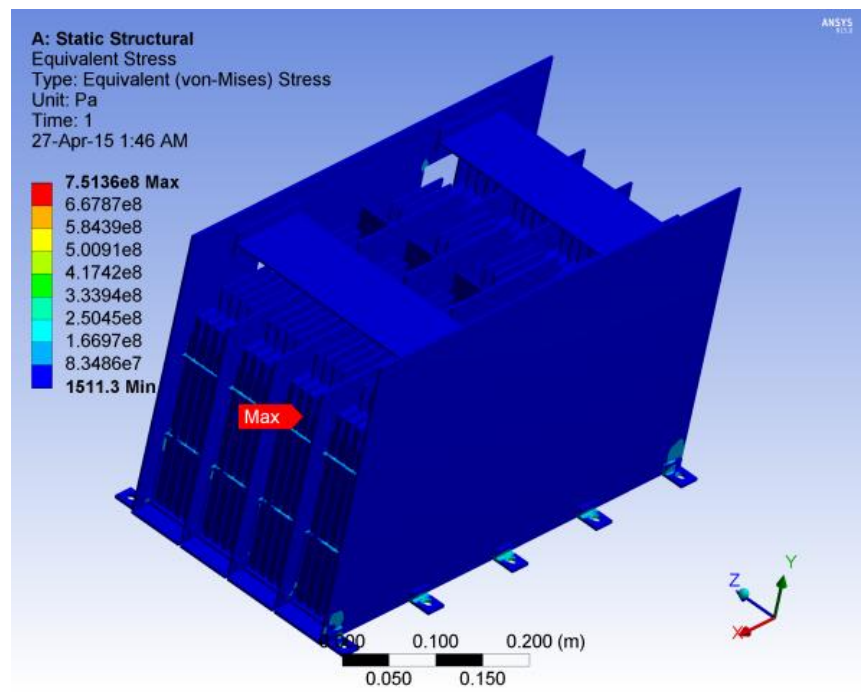

Stress analysis of the pack for $40 \mathrm{~g}$ acceleration in longitudinal direction

Max Stress: 7.51e8 Pa

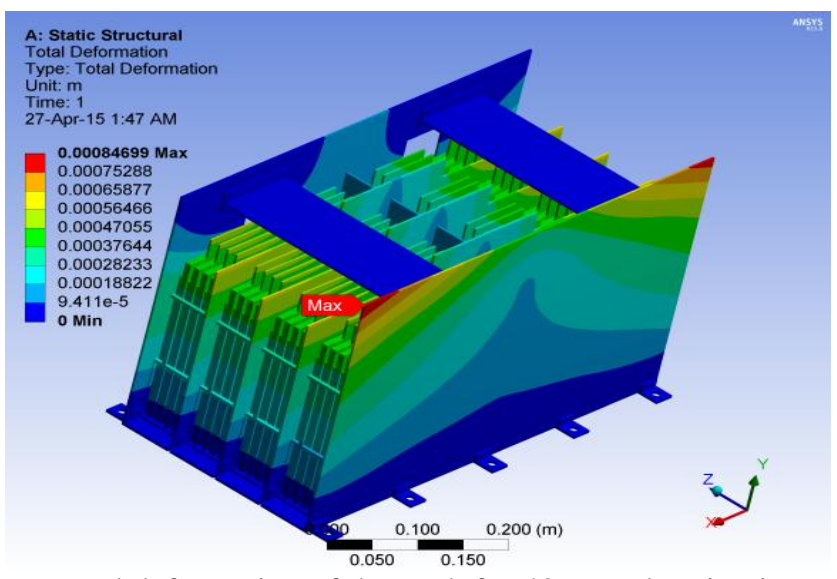

Total deformation of the pack for $40 \mathrm{~g}$ acceleration in longitudinal direction

Max Deformation: 8.46e-4 m a. The attachment of any brackets to the container is at least as strong as $20 \mathrm{kN} \times$ the number of fasteners per bracket

b. If brackets are bolted to the container, that there is sufficient shear area under the head of the bolts/washers, so the perimeter shear strength is $>=20 \mathrm{kN} \times$ the number of fasteners per bracket[4]

So analysis of the mounting brackets was performed by applying $20 \mathrm{kN}$ force on each bolt hole in longitudinal. Lateral and vertical direction respectively. The material chosen for the brackets was mild steel. The second point need not be proven because the brackets are welded on the walls of the container.

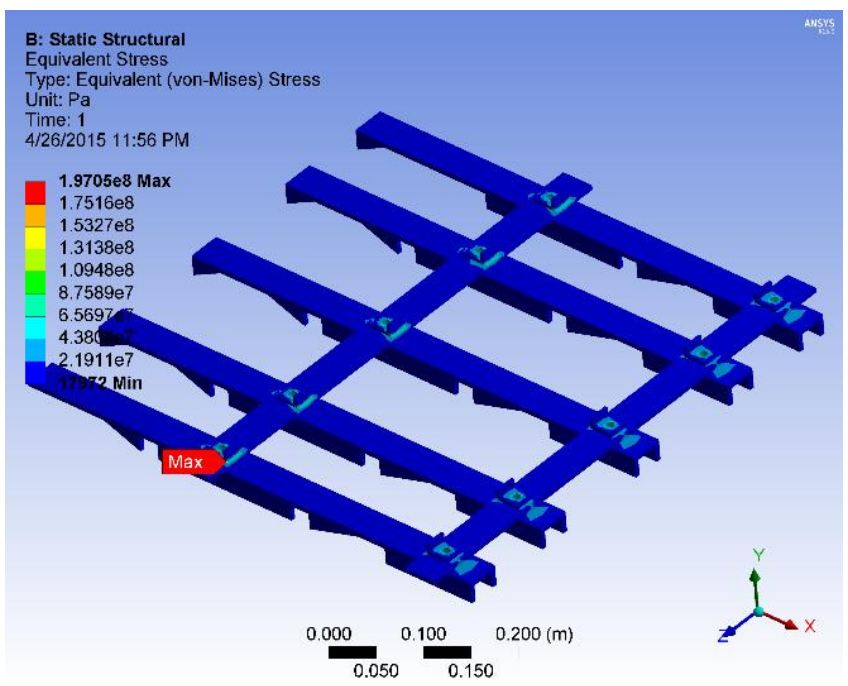

Stress analysis in longitudinal direction Max Stress: 1.97e8Pa

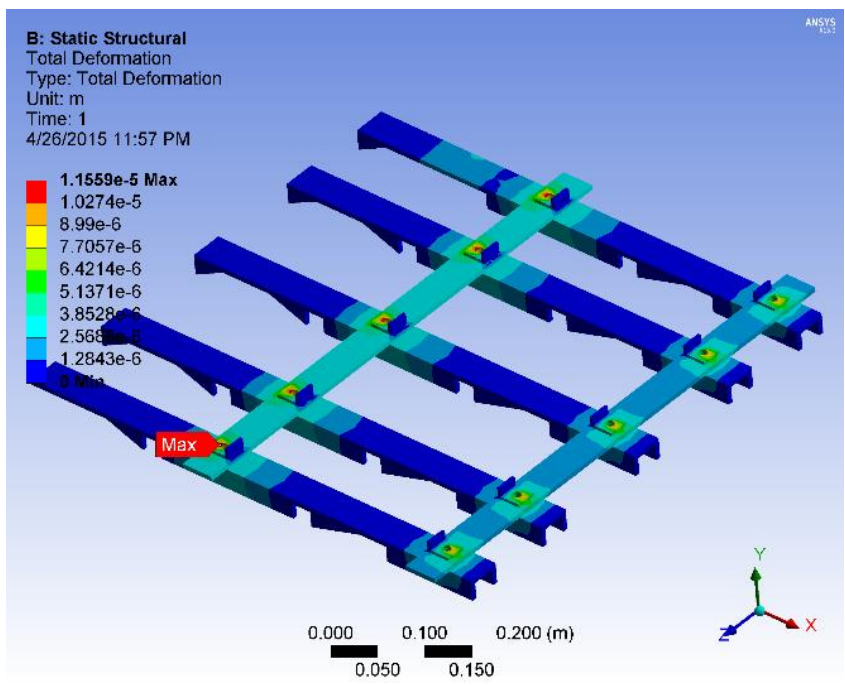

Deformation analysis in vertical direction Max Deformation: 1.15e-5 m

For accumulator attachments the following points must be proved: 


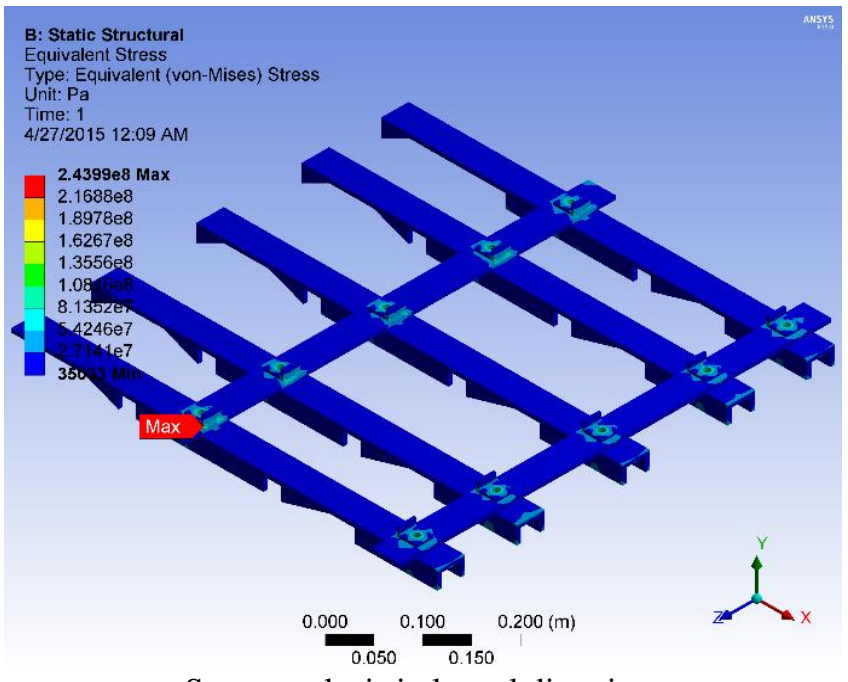

Stress analysis in lateral direction

Max Stress: $2.43 \mathrm{e} 8 \mathrm{~Pa}$

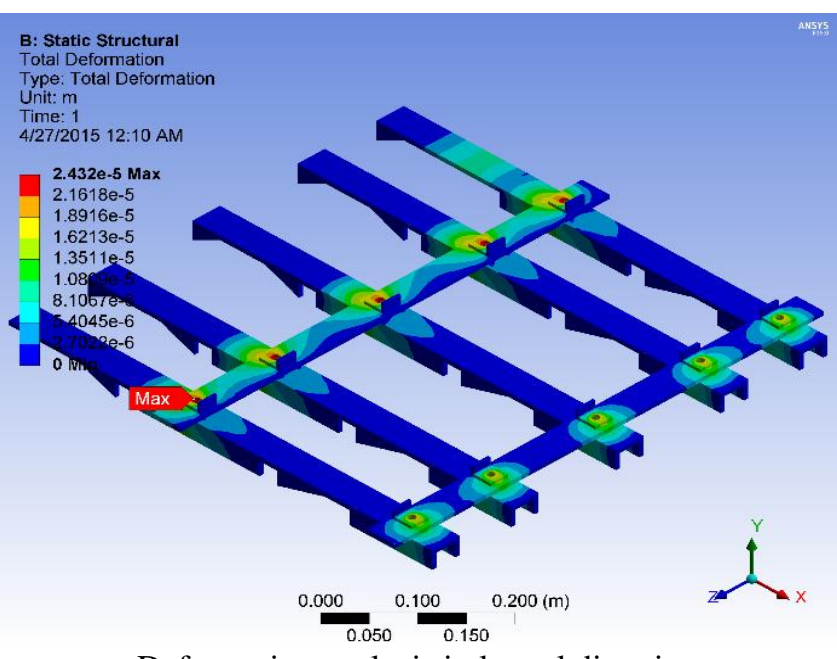

Deformation analysis in lateral direction

Max Deformation: 2.432e-5 m

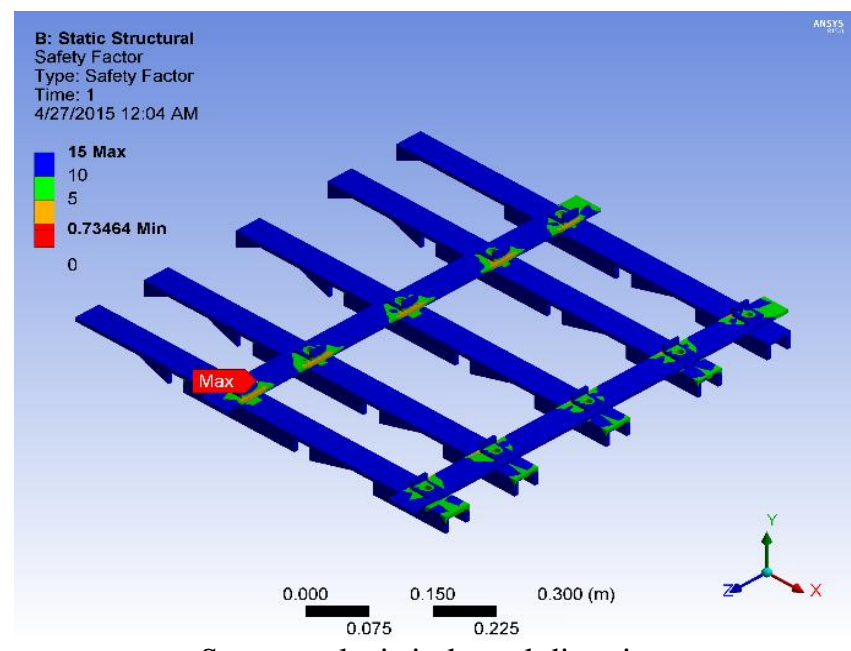

Stress analysis in lateral direction

FOS: 0.73

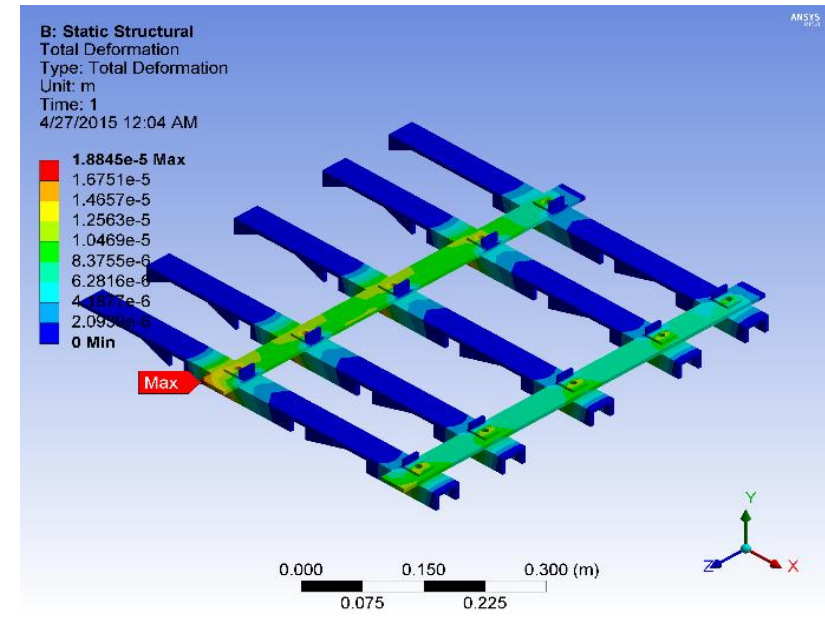

Deformation analysis in lateral direction Max Deformation: $1.88 \mathrm{e}-5 \mathrm{~m}$

\section{CONCLUSIONS}

The battery pack was designed and manufactured with the help of Optimum Lap, MATLAB, Solid Works and ANSYS. The battery pack was designed according to the powertrain and endurance requirements keeping in mind feasibility in manufacturing and availability of resources.

\section{ACKNOWLEDGEMENT}

We would like to thank Team Ojas, VIT University Vellore and Prof. Vijayakumar D their continuous help, support and guidance throughout the project.

\section{REFERENCES}

[1]. Design and Analysis of a Battery for a Formula Electric Car-Samuel Reineman

[2]. Module design and fault diagnosis in electric vehicle batteries-Gregory. J. Offer*, Vladimir. Yufit, David. A. HoweyI, Billy. Wu and Nigel. P. Brandon

[3]. McGraw Hill-Handbook of Batteries

[4]. 2015-16 FSAE Rules

[5] Kokam-SLPB (Superior Lithium Polymer Battery) Technical Specification

[6] 95 Performance Graphs for AGNI MOTORS

\section{BIOGRAPHIES}

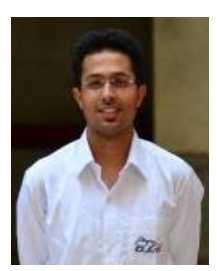

Ujjwal Ashish is doing his B. Tech in Electrical and Electronics engineering from VIT University, Vellore. He along with his team represented India and VIT University in Formula Student, Germany-2015. His areas of interest are Power system Analysis and Protection Switchgear.

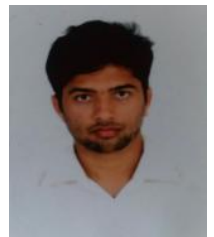

Bishav Raj is doing his B.Tech in Mechanical Engineering from VIT University, Vellore. He along with his team represented India and VIT University in Formula Student, Germany-2015. His areas of interests include Kinetics of Machinery,

Dynamics of Machinery and Strength of Materials. 
Abhishek Kumar is doing his B. Tech in

Electrical and Electronics engineering from VIT University, Vellore. His main areas of interest are Automotive Electronics, Control System. 